\title{
Upregulation of minichromosome maintenance complex component 3 during epithelial-to-mesenchymal transition in human prostate cancer
}

\author{
Paul A. Stewart ${ }^{1, *}$, Zahraa I. Khamis ${ }^{1,4, *}$, Haiyen E. Zhau2, ${ }^{2}$, Peng Duan², Quanlin Li², \\ Leland W.K. Chung ${ }^{2}$ and Qing-Xiang Amy Sang ${ }^{1,3}$ \\ ${ }^{1}$ Department of Chemistry \& Biochemistry, Florida State University, Tallahassee, FL, United States of America \\ ${ }^{2}$ Samuel Oschin Comprehensive Cancer Institute, Cedars-Sinai Medical Center, Los Angeles, CA, United States of America \\ ${ }^{3}$ Institute of Molecular Biophysics, Florida State University, Tallahassee, FL, United States of America \\ ${ }^{4}$ Laboratory of Cancer Biology and Molecular Immunology, Department of Biochemistry, Faculty of Sciences, Lebanese \\ University, Beirut, Lebanon \\ *These authors have contributed equally to this work \\ Correspondence to: Qing-Xiang Amy Sang, email: qxsang@chem.fsu.edu \\ Haiyen E. Zhau, email: haiyen.zhau@cshs.org \\ Keywords: epithelial-to-mesenchymal transition, minichromosome maintenance complex proteins, metastasis, androgen \\ receptor, proteomics \\ Received: September 06, 2016 \\ Accepted: March 08, 2017 \\ Published: April 05, 2017 \\ Copyright: Stewart et al. This is an open-access article distributed under the terms of the Creative Commons Attribution License \\ 3.0 (CC BY 3.0), which permits unrestricted use, distribution, and reproduction in any medium, provided the original author and \\ source are credited.
}

\section{ABSTRACT}

Metastasis is often associated with epithelial-to-mesenchymal transition (EMT). To understand the molecular mechanisms of this process, we conducted proteomic analysis of androgen-repressed cancer of the prostate (ARCaP), an experimental model of metastatic human prostate cancer. The protein signatures of epithelial $\left(\mathrm{ARCaP}_{\mathrm{E}}\right)$ and mesenchymal $\left(\mathrm{ARCaP}_{\mathrm{M}}\right)$ cells were consistent with their phenotypes. Importantly, the expression of mini-chromosome maintenance 3 (MCM3) protein, a crucial subunit of DNA helicase, was significantly higher in $\mathrm{ARCaP}_{M}$ cells than that of ARCaP $P_{E}$ cells. This increased MCM3 protein expression level was verified using Western blot analysis of the ARCaP cell lineages. Furthermore, immunohistochemical analysis of MCM3 protein levels in human prostate tissue specimens showed elevated expression in bone metastasis and advanced human prostate cancer tissue samples. Subcutaneous injection experiments using $\mathrm{ARCaP}_{\mathrm{E}}$ and $\mathrm{ARCaP}_{\mathrm{M}}$ cells in a mouse model also revealed increased MCM3 protein levels in mesenchymal-derived tumors. This study identifies MCM3 as an upregulated molecule in mesenchymal phenotype of human prostate cancer cells and advanced human prostate cancer specimens, suggesting МСM 3 may be a new potential drug target for prostate cancer treatment.

\section{INTRODUCTION}

Prostate cancer $(\mathrm{PCa})$ is the most common nonskin malignancy and a major leading cause of cancer deaths among men in the Western world. An estimated 180,000 men would be diagnosed with prostate cancer in 2016 with 26,000 estimated deaths occurring from the disease in the USA [1]. Most patients who die from prostate cancer develop lethal castration-resistant or androgen independent metastatic disease that fails to respond to available therapeutics. A mechanistic understanding of the metastatic cascade can help identify new treatment strategies, identify patients with aggressive lesions, and control the dissemination of cancer cells to other parts of the body to improve prostate cancer patient survival. Metastasis of tumor cells to distant sites is believed to involve epithelialto-mesenchymal transition (EMT) by which immotile epithelial cells become motile, aggressive, and metastatic [2]. In prostate cancer, EMT has been 
described as a notable feature of the androgen repressed prostate cancer $\left(\mathrm{ARCaP}_{\mathrm{E}} / \mathrm{ARCaP}_{\mathrm{M}}\right)$ cell line model. This $\mathrm{ARCaP}$ prostate cancer cell line not only represents a relevant EMT model but also mimics the clinical course of prostate cancer metastasis. The epithelial-like $\left(\mathrm{ARCaP}_{\mathrm{E}}\right)$ cells are isolated from parental ARCaP cells and induced to transition to mesenchymal phenotype $\left(\mathrm{ARCaP}_{\mathrm{M}}\right)$ upon exposure to soluble growth factors or surrounding skeletal microenvironment [3]. Recent studies highlight the molecular and behavioral signatures of this ARCaP EMT model [4, 5]. Understanding the molecular basis of EMT will provide indispensable insights into the metastatic process and valuable prognostic and therapeutic targets.

Minichromosome maintenance proteins encompass a group of ten factors that function in initiation and elongation of DNA replication [6]. MCM1 and MCM10 do not belong to this family but also play a role in DNA synthesis. MCM1 is a transcription factor that can affect DNA synthesis [7], and MCM10 functions in initiation of DNA replication [8]. While MCM8 is presumed to possess a helicase activity during elongation of DNA replication [9], the role of MCM9 has not yet been addressed [10]. MCM2-7 are six structurally related proteins crucial for initiation of DNA replication. During late $\mathrm{M}$ /early $\mathrm{G} 1$ phases, inactive MCM2-7 proteins are recruited to DNA and loaded on replication origins as a double hexamer to preserve bi-directionality of replication forks $[11,12]$. At this point, the six MCM subunits associate with other proteins to form the prereplication complex. In $\mathrm{S}$ phase, the double hexamer interacts with the pre-initiation complex proteins and serves as a part of the replicative helicase unwinding the DNA and "licensing" the origin to undergo precisely one replication per one cell cycle round [13]. Recently, Frigola et al. showed that MCM3 is indispensable and sufficient to affect recruitment and loading of the double hexamer on DNA [12]. This MCM subunit is used as a proliferation marker that can determine tumor growth propensities. Elevated expression of MCM3 is also correlated with poor prognosis and more advanced stages in ovarian cancer, squamous cell carcinoma, and malignant melanoma [14-16]. These findings underscore the function of MCM3 in cancer progression and suggest a putative role of this protein in prostate cancer metastasis.

This study aims to further understand the molecular mechanisms of prostate cancer metastasis using an ARCaP cell line EMT model, to find new targets for the development of more effective treatment strategies, and to improve clinical outcomes of prostate cancer patients. Biochemical analyses of our EMT model revealed increased expression of MCM3 upon EMT in the ARCaP cell line model and in human metastatic prostate tissues. This finding suggests a pivotal role of MCM3 during EMT and prostate cancer metastasis.

\section{RESULTS}

\section{Protein expression profile in the ARCaP EMT model}

Proteomic analysis was conducted to identify EMT related changes in protein expression in the ARCaP human prostate cancer cell line model. A set of 1,152 proteins were identified in $\mathrm{ARCaP}_{\mathrm{E}}$ and $\mathrm{ARCaP}_{\mathrm{M}}$ in our proteomics approach (Supplementary Table 1). Only 64 proteins were differentially expressed between the two cell lines with a $\mathrm{P}$-value $<0.05$ and a fold-change of at least 1.5 (Supplementary Table 1). A total of 35 proteins were upregulated and 29 proteins were downregulated in $\mathrm{ARCaP}_{\mathrm{M}}$ compared to $\mathrm{ARCaP}_{\mathrm{E}}$. A selection of the proteins with the highest fold-changes is listed in Table 1. Consistent with their respective phenotypes, $\mathrm{ARCaP}_{\mathrm{E}}$ expressed significantly higher levels of epithelial markers such as tight junction protein TJP1 (P=0.004, -2.69 $\log _{2}$ fold-change; also known as ZO-1) and keratins KRT1 and KRT8 $\left(\mathrm{P}=0.005,-1.95 \log _{2}\right.$ fold-change; $\mathrm{P}=0.024,-1.32$ $\log _{2}$ fold-change, respectively). The $\mathrm{ARCaP}_{\mathrm{M}}$ upregulated proteins were predominantly correlated with the mesenchymal and aggressive phenotype. They expressed higher levels of vimentin (VIM), matrix metalloproteinase 1 (MMP1) and major vault protein (MVP). The expression of the mesenchymal marker vimentin was not significant ( $\mathrm{P}=0.09,0.72 \log 2$ fold-change; Supplementary Table 1), but was in agreement with a previous study of $\mathrm{ARCaP}_{\mathrm{E}}$ and $\mathrm{ARCaP}_{\mathrm{M}}$ (0.85 $\log _{2}$ fold-change) [17]. The elevated expression of matrix metalloproteinase 1 in $\mathrm{ARCaP}_{\mathrm{M}}$ (MMP1; $\mathrm{P}=0.036,1.61 \log _{2}$ fold-change) is consistent with the functions attributed to this metalloprotease in prostate cancer progression and metastasis [18]. $\mathrm{ARCaP}_{\mathrm{M}}$ showed high levels of major vault protein (MVP or LRP) (P $=0.002,1.41 \log 2$ fold-change), a protein that is increased in advanced prostate cancer and expressed in drug resistant cell lines and various types of cancers $[19,20]$.

\section{Pathway analysis of differentially expressed proteins}

To gain mechanistic insight into the underlying biology of $\mathrm{ARCaP}_{\mathrm{E}}$ and $\mathrm{ARCaP}_{\mathrm{M}}$ cells, altered proteins (at least 1.5 fold higher in either cell line) were input into GeneGO MetaCore (Thomson Reuters, https://portal. genego.com/) for pathway analysis, and a number of pathways were enriched (false discovery rate or FDR < 0.05) (Table 2, Supplementary Table 2). Four of the top 10 pathways were related to cell adhesion and two were related to cell cycle. One of the significantly altered pathways was Cell cycle_start of DNA replication in early $S$ phase (pathway FDR $=0.0060$; Table 2), which included MCM3, MCM6, and MCM7. All of these MCM family members were differentially and highly expressed in $\mathrm{ARCaP}_{\mathrm{M}}$ compared to $\mathrm{ARCaP}_{\mathrm{E}}$ (Table 1). 
Table 1: Differentially expressed proteins between $\mathrm{ARCaP}_{\mathrm{E}}$ and $\mathrm{ARCaP}_{\mathrm{M}}$

\begin{tabular}{lcc}
\hline Gene Symbol & Log $_{2}$ Fold-change & T-test P-Value \\
\hline RBM3 & 1.72 & 0.002 \\
MMP1 & 1.61 & 0.036 \\
MCM3 & 1.49 & 0.015 \\
MVP & 1.41 & 0.002 \\
MCM7 & 1.40 & 0.048 \\
MCM6 & 1.07 & 0.047 \\
KRT8 & -1.32 & 0.024 \\
KRT1 & -1.95 & 0.005 \\
TJP1 & -2.69 & 0.004 \\
\hline
\end{tabular}

$\log _{2}$ fold-change is calculated as $\log _{2}\left(\mathrm{ARCaP}_{\mathrm{M}} / \mathrm{ARCaP}_{\mathrm{E}}\right)$.

Abbreviations: RBM3, RNA binding motif protein 3; MMP1, matrix metalloproteinase-1; MCM3, minichromosome maintenance complex component 3; MVP, major vault protein; MCM7, minichromosome maintenance complex component 7; MCM6, minichromosome maintenance complex component 6; KRT8, keratin 8; KRT1, keratin 1; TJP1, tight junction protein 1.

Table 2: Top altered pathways between $\mathrm{ARCaP}_{\mathrm{E}}$ and $\mathrm{ARCaP}_{\mathrm{M}}$

\begin{tabular}{lll}
\hline Pathway & Proteins Found in Pathway & FDR* \\
\hline $\begin{array}{l}\text { Cell adhesion_Role of tetraspanins in the } \\
\text { integrin-mediated cell adhesion }\end{array}$ & 8 & 0.0004 \\
$\begin{array}{l}\text { Cell cycle_Chromosome condensation in } \\
\text { prometaphase }\end{array}$ & 6 & 0.0009 \\
$\begin{array}{l}\text { Cytoskeleton remodeling_Keratin } \\
\text { filaments }\end{array}$ & 7 & 0.0014 \\
$\begin{array}{l}\text { Cell cycle_Start of DNA replication in } \\
\text { early S phase }\end{array}$ & 6 & 0.0060 \\
$\begin{array}{l}\text { Blood coagulation_Platelet microparticle } \\
\text { generation }\end{array}$ & 8 & 0.0104 \\
$\begin{array}{l}\text { Cell adhesion_Endothelial cell contacts } \\
\text { by non-junctional mechanisms }\end{array}$ & 5 & 0.0104 \\
$\begin{array}{l}\text { Cell adhesion_Chemokines and adhesion } \\
\text { Neurophysiological process_Receptor- } \\
\text { mediated axon growth repulsion }\end{array}$ & 9 & 0.0181 \\
$\begin{array}{l}\text { wtCFTR and deltaF508 traffic / } \\
\text { Membrane expression (normal and CF) }\end{array}$ & 6 & 0.0214 \\
$\begin{array}{l}\text { Cell adhesion_Alpha-4 integrins in cell } \\
\text { migration and adhesion }\end{array}$ & 6 & 0.0215 \\
\hline
\end{tabular}

*FDR: False discovery rate or adjusted p-value.

\section{Overexpression of $\mathrm{MCM} 3$ in $\mathrm{ARCaP}_{\mathrm{M}}$ cells and human prostate cancer tissues}

Interestingly, upregulation of three of the six homologous MCM subunits, MCM3 $(\mathrm{P}=0.015,1.49$ $\log 2$ fold-change), MCM6 ( $\mathrm{P}=0.047,1.07 \log 2$ foldchange), and $\mathrm{MCM} 7$ ( $\mathrm{P}=0.048,1.40$ log2 fold-change) proteins was observed in $\mathrm{ARCaP}_{\mathrm{M}}$ cells. $\mathrm{MCM} 3$ showed the most significant difference and was further pursued. Western blotting analyses of total and nuclear proteins 
confirmed the abundant expression of $\mathrm{MCM} 3$ in $\mathrm{ARCaP}_{\mathrm{M}}$ cells (Figure 1). These results were validated in vivo using immunohistochemical analysis of tumors generated from subcutaneous injection of $\mathrm{ARCaP}_{\mathrm{E}}, \mathrm{ARCaP}_{\mathrm{M}}$, and $\mathrm{ARCaP}_{\mathrm{M} \text {-Bone }}$ into nude mice (Figure 2). $\mathrm{ARCaP}_{\mathrm{M} \text {-Bone }}$ and $\mathrm{ARCaP}_{\mathrm{M}-\mathrm{C} 2}$ cells are derived from $\mathrm{ARCaP}_{\mathrm{M}}$ cell-induced bone metastatic tissues after two rounds of intracardiac inoculation of athymic mice [21]. Compared to $\mathrm{ARCaP}_{\mathrm{E}}$ tumors, $\mathrm{ARCaP}_{\mathrm{M}}$ and $\mathrm{ARCaP}_{\mathrm{M}-\mathrm{B} o n e}$ tumors displayed higher levels of MCM3 protein. These data suggest that MCM3 upregulation is correlated with the increased in vivo metastatic ability of the ARCaP EMT model.

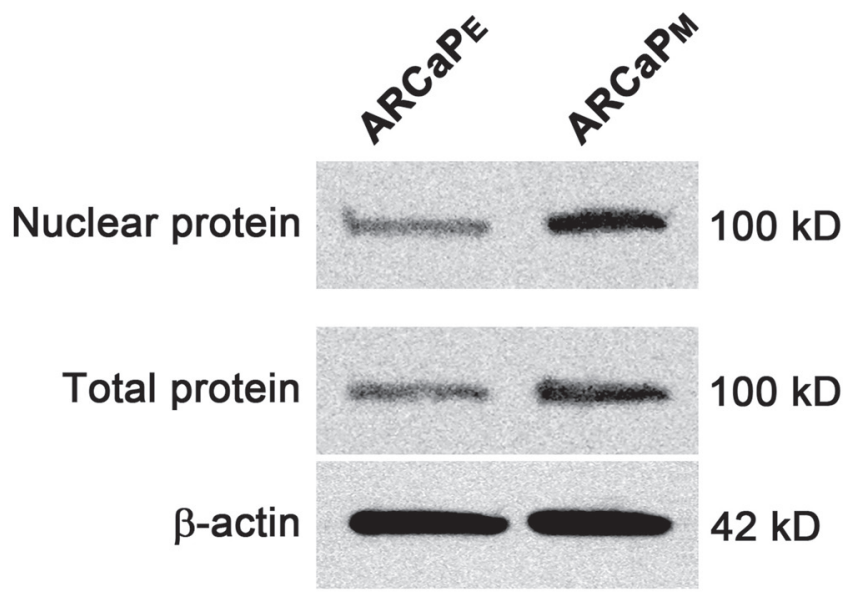

Figure 1: Western blot of $\mathrm{MCM} 3$ in $\mathrm{ARCaP}_{\mathrm{E}}$ and $\mathrm{ARCaP}_{\mathrm{M}}$ cells. Total and nuclear proteins were analyzed for MCM3 expression. Beta-actin was used as a control.

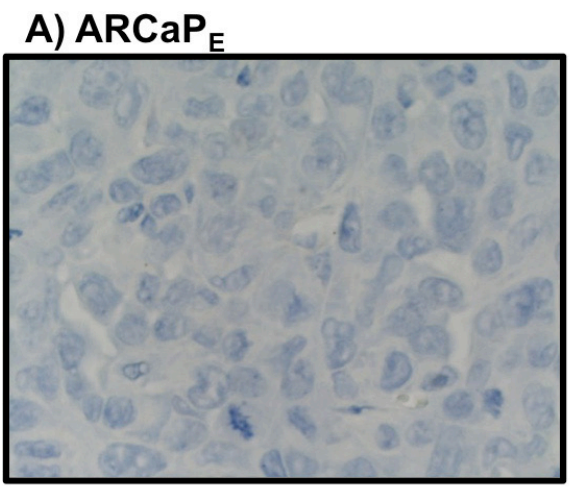

C) $\mathrm{ARCaP}_{\mathrm{M}}$-Bone

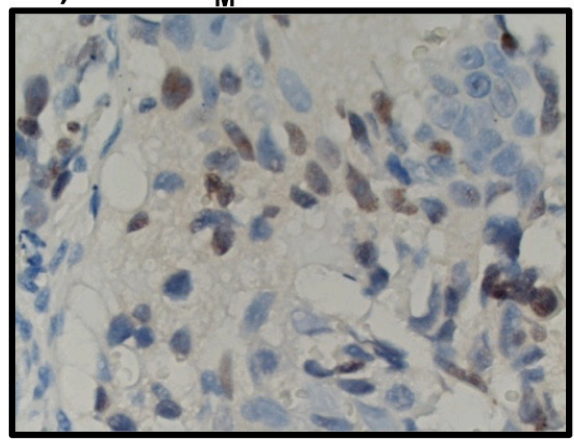

B) ARCaP $_{M}$

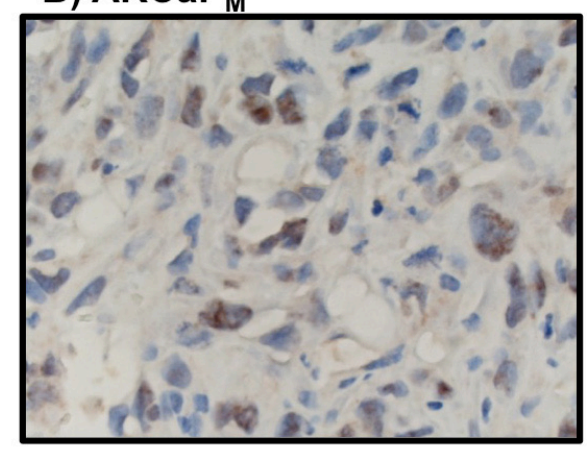

D) Patient Bone Metastases

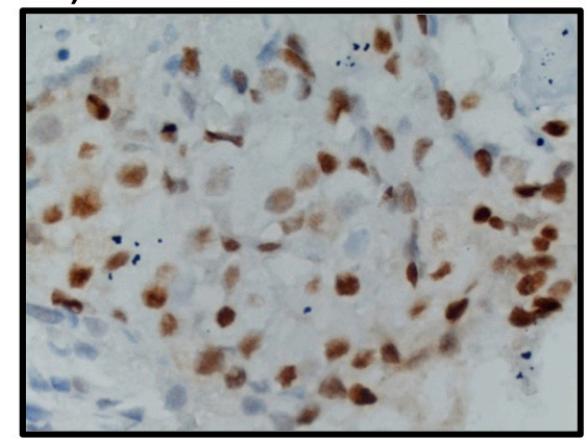

Figure 2: $\mathbf{M C M} 3$ expression profiling in $\mathbf{A R C a P}_{\mathbf{E}}$ cells $(\mathbf{A}), \mathrm{ARCaP}_{\mathrm{M}}$ cells $(\mathbf{B}), \mathrm{ARCaP}_{\mathrm{M}-\mathrm{Bone}}$ cells $(\mathbf{C})$ and patient bone metastasis (D). MCM3 expression is higher in primary tumor induced by subcutaneous injection of $\mathrm{ARCaP}_{\mathrm{M}}$ than by $\mathrm{ARCaP}_{\mathrm{E}}(\mathbf{A}-\mathbf{B})$. $\mathrm{MCM} 3$ is highly expressed in $\mathrm{ARCaP}_{\mathrm{M}-\text { bone }}(\mathbf{C})$ and in three out of four human bone metastatic tissues from prostate cancer patients (D). Images were taken at $400 \mathrm{X}$ magnification. 
Additional in vivo validation of MCM3 results was sought in a small cohort of metastatic human bone tissue specimens. Consistently, three out of four human metastatic prostate tissues showed significant high expression of MCM3 (Figure 2D). To assess the significance of our ARCaP EMT model for clinical prostate cancer progression, we evaluated the expression of MCM3 in normal prostate $(n=12)$, benign prostatic hyperplasia $(\mathrm{BPH}, \mathrm{n}=6)$, and primary prostate carcinoma tissues $(\mathrm{n}=$ 12). MCM3 was observed to be absent in normal prostate, barely observed in benign tumor, and highly expressed in late stage prostate cancer (Figure 3). Semi-quantitative analysis of MCM3 expression in the different human prostate tissues showed the lowest MCM3 expression in normal tissue and the highest in high-grade prostate cancer. There was a significant difference in expression between normal and cancerous prostate $(\mathrm{P}=0.0001), \mathrm{BPH}$ and cancer $(\mathrm{P}=0.01)$, but not between normal and $\mathrm{BPH}$ $(P=0.0866)$ (Figure 4). These data further supported our findings of a positive correlation between elevated MCM3 protein levels and increased aggressiveness of the disease.

\section{DISCUSSION}

Despite recent advances in prognosis, diagnosis and treatment of prostate cancer, development of lethal skeletal metastases remains a clinical challenge. Current treatment strategies are directed at patients with localized prostate carcinomas and offer only modest remission for those with more aggressive lesions [22]. We urgently need to understand the mechanisms by which prostate tumor cells disseminate to distant sites. Given the association of metastasis with EMT, it stands to reason that dissecting the molecular signatures of the EMT process will reveal valuable targets for prostate cancer therapy and clinical research. We used the ARCaP human prostate cancer cell lineage as an experimental EMT model of clinical prostate cancer metastasis [3]. $\mathrm{ARCaP}_{\mathrm{E}}$ and $\mathrm{ARCaP}_{\mathrm{M}}$ cells are derived from genetically identical cells isolated from the same human prostate cancer patient with bone metastases [3, 23, 24]. However, they exhibit different morphology, gene expression profiles and behavioral characteristics. $\mathrm{ARCaP}_{\mathrm{M}}$ cells have increased expression of mesenchymal markers such as vimentin, $\mathrm{N}$-cadherin, and RANKL; decreased epithelial markers like E-cadherin; increased proliferation compared to $\mathrm{ARCaP}_{\mathrm{E}}$; and higher propensity for bone metastasis [3, 23, 25]. Conversely, $\mathrm{ARCaP}_{\mathrm{E}}$ cells display epithelial morphology with lower invasion, migration, growth rate, and metastatic potential $[3,23,25]$. Both $\mathrm{ARCaP}_{\mathrm{E}}$ and $\mathrm{ARCaP}_{\mathrm{M}}$ cells are derived from the parental ARCaP cells which express low levels of androgen receptor and prostate specific antigen, and are repressed by androgens [24].

Our study showed elevated expression of three members of the MCM family of proteins, MCM3, MCM6, and $\mathrm{MCM}$, in $\mathrm{ARCaP}_{\mathrm{M}}$ as compared to $\mathrm{ARCaP}_{\mathrm{E}}$ cells.
While MCM6 was reported to be prognostic marker in a few malignancies [26], MCM7 is extensively studied in human prostate cancer tissues and is correlated with higher propensities for prostate cancer progression, invasion, and metastasis [27, 28]. We selected MCM3 for further study based on lack of reports in the literature on the expression of MCM3 in prostate cancer, and on its critical importance in the cell cycle. In our proteomics and Western blotting analyses, MCM3 was upregulated upon EMT in the ARCaP prostate cancer cell model (Figure 1). This upregulation corroborated the in vivo investigation of tumors generated from subcutaneous injection of $\mathrm{ARCaP}_{\mathrm{E}}, \mathrm{ARCaP}_{\mathrm{M}}$, and $\mathrm{ARCaP}_{\mathrm{M} \text {-Bone }}$ (Figure 2) in nude mice. To investigate the clinical significance of MCM3 in human prostate cancer progression, immunohistochemical analysis was performed on normal human prostate, benign prostatic hyperplasia, primary prostate cancer, and human bone metastatic prostate cancer tissues (Figures 2D and 3 ). In accord with our previous results, expression of MCM3 was significantly increased in primary tumors and further upregulated in bone metastases, suggesting a pivotal role of MCM3 in prostate cancer progression and metastasis.

In the majority of cases observed in the clinic, human prostate cancer progression proceeds from an androgen-dependent to an androgen-independent state. Later stages of advanced human prostate cancer are either androgen-insensitive or androgen-repressed. One of the suggested molecular mechanisms that delineates this androgen-repressed phenotype in our EMT model is the expression of phosphorylated androgen-induced proliferation inhibitor (APRIN) in ARCaP cells, as we reported previously [5]. In the present study, we hypothesize another plausible mechanism that involves the interplay of MCM3, MCM7, and androgen receptor (AR). In our EMT ARCaP model, both MCM3 and MCM7 proteins of the replicative DNA helicase were elevated in $\mathrm{ARCaP}_{\mathrm{M}}$ cells. A recent study indicated that the C-terminus of MCM3 is crucial for recruitment of all MCM2-7 proteins to DNA [12]. This MCM3 tail is required for the loading of the double hexamer on DNA to "license" replication [6]. Cells lacking MCM3 fail to proceed into $\mathrm{S}$ phase and proliferate. All of these data suggest MCM3 as an inevitable proliferation marker affecting DNA synthesis and eventually cell division. Several pathways and constituent proteins have been implicated in inducing EMT in cancerous cells. These pathways are typically active in a number of other processes that include cell proliferation, but the link between proliferation-associated proteins like MCM3 and EMT is not well understood [29]. One possibility is that the greater the number of proliferating mesenchymal cells with migratory and invasive phenotype, the more of these aggressive cells are available to metastasize.

One of the most extensively studied MCM proteins, MCM7, is part of DNA helicase and is found to interact 
A) Normal

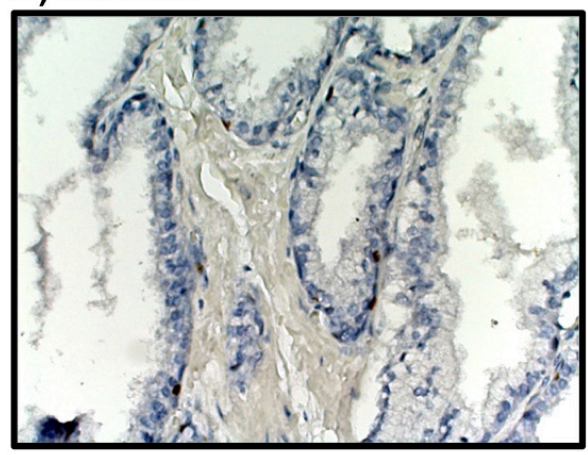

C) Primary cancer (Gleason $3+3$ )

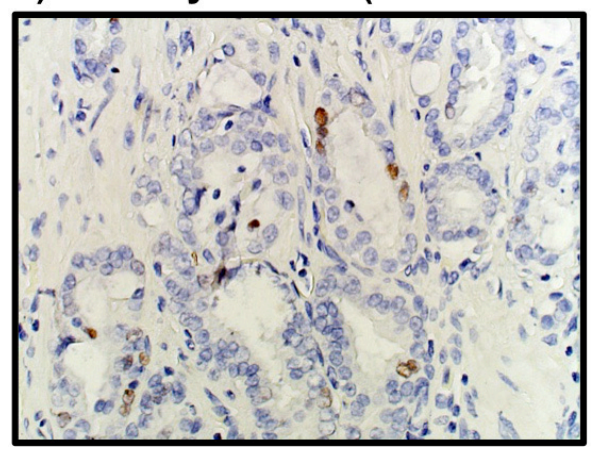

\section{B) $\mathrm{BPH}$}
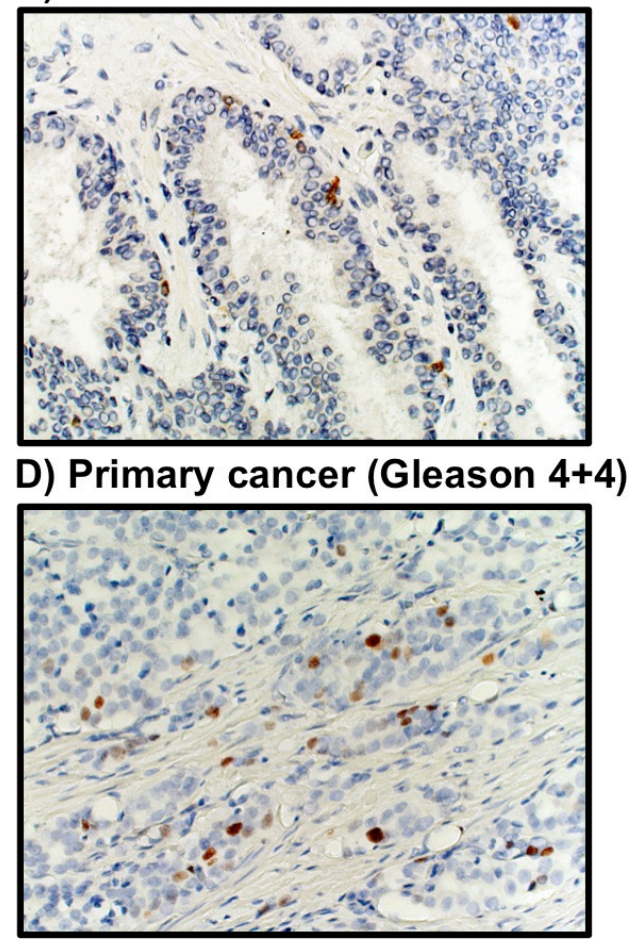

Figure 3: MCM3 expression in human prostate cancer. MCM3 expression was visually absent in 12 normal prostate tissues (A), barely expressed in 6 benign prostatic hyperplasia tissues (B), and significantly increased in 12 prostate cancer clinical specimens (C-D). Images were taken at $200 \mathrm{X}$ magnification.

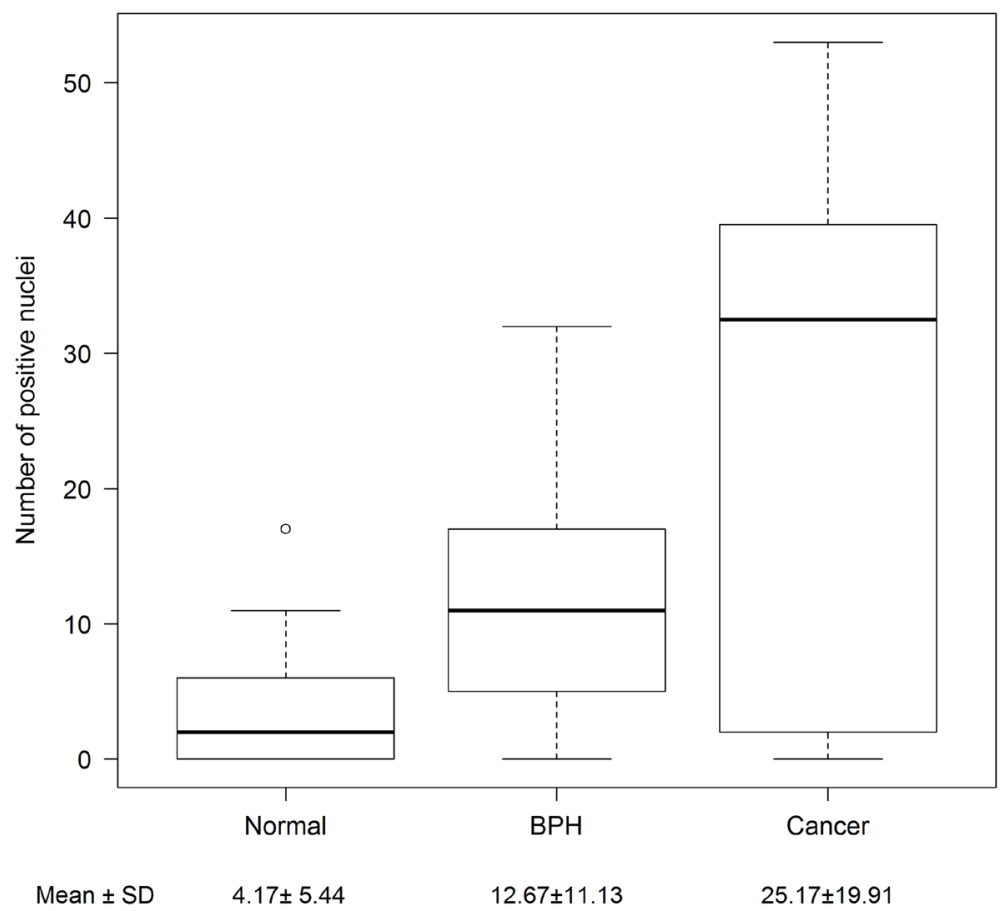

Figure 4: Semi-quantitative analysis of MCM3 expression in human samples. The number of MCM3 positive nuclei from normal $(n=12)$, benign $(n=6)$, and cancerous $(n=12)$ patient tissue samples were counted in ten random 20X microscopic fields. Differences between normal, benign, and cancerous samples were determined using a Poisson regression model. Normal prostate and benign prostatic hyperplasia showed no significant difference in expression $(p=0.0866)$. MCM3 differential expression is significant between benign and cancer $(\mathrm{p}=0.01)$ and normal and cancer $(\mathrm{p}=0.0001)$. Mean and standard deviations are shown. 
with AR [30]. The interaction between AR and MCM7 is vital for gene expression or repressor activity of androgen. This AR/MCM7 complex acts as a co-replication factor affecting cell proliferation and as a co-transcription factor controlling the expression of AR-responsive genes. The availability of androgens inhibits MCM7 expression and causes cell growth arrest. Conversely, the absence of androgens results in an $\mathrm{AR} / \mathrm{MCM} 7$ interaction that induces the MCM complex to initiate DNA replication [30]. Based on all these findings, we consider that the increased metastatic potential of $\mathrm{ARCaP}_{\mathrm{M}}$ cells is partially due to increased levels of MCM3 and MCM7, because the more cells proliferate the more cells with EMT phenotype are available for spreading to other parts of the body. Elevated MCM3 and MCM7 proteins are speculated to interact with $\mathrm{AR}$, affecting cell proliferation, migration, and androgen repression. Whether MCM3 interacts directly or indirectly with AR remains to be further investigated.

This study sheds light on EMT and metastasis in human prostate cancer using the $\mathrm{ARCaP}_{\mathrm{E}} / \mathrm{ARCaP}_{\mathrm{M}}$ cell line model and human prostate cancer tissue specimens. We found an elevated expression of the proliferation marker MCM3 in $\mathrm{ARCaP}_{\mathrm{M}}$ compared to $\mathrm{ARCaP}_{\mathrm{E}}$ cells and during the progression of prostate cancer from primary tumor to metastatic disease. This upregulation is hypothesized to involve an interaction with AR either directly or indirectly through MCM7. Collectively, our data suggest a pivotal role of MCM3 in prostate cancer metastasis and a possible AR-MCM7-MCM3 interaction that may be responsible for the growth, metastasis, and androgen-repressed phenotype of late stage human prostate cancer. Understanding the molecular mechanisms and the clinical and pathological parameters of prostate cancer metastasis is of utmost importance to identify new therapeutic targets and improve patient outcomes.

\section{MATERIALS AND METHODS}

\section{Cell culture and proteomics analysis}

Biological triplicates of $\mathrm{ARCaP}_{\mathrm{E}}$ and $\mathrm{ARCaP}_{\mathrm{M}}$ were cultured in Dulbecco's Modified Eagle's Medium (Sigma Product \# 5523) supplemented with 3.7 grams sodium bicarbonate in a humid incubator at $37^{\circ} \mathrm{C}$ and $5 \% \mathrm{CO}_{2}$. Cells were grown until prior to confluence and harvested using a lysis buffer (4\% CHAPS, 8M Urea) supplemented with Halt protease and phosphatase inhibitor (ThermoScientific Product \# 78443) and scraping. After scraping and collection, lysate was mixed for 45 minutes followed by several freeze-thaw cycles to ensure thorough lysis. Lysate was centrifuged and the supernatant was collected for subsequent proteomic analysis.

Buffer exchange and processing of lysate for proteomic analysis was performed according to a modified filter-aided sample preparation (FASP) protocol with a $30 \mathrm{kDa}$-cutoff centrifugal filter unit (VWR Product \# 82031-352) [31]. Samples were digested with mass spectrometry grade trypsin (ThermoScientific Product \# 90059) for 24 hours using a 1:100 enzyme to protein ratio. Protein concentrations of FASP-prepped, digested samples were determined using a bicinchoninic acid assay kit (ThermoScientific Product \# 23227), and samples were then uniformly loaded into a nano high performance liquid chromatography column packed with $\mathrm{C} 18$ reversed phase silica coupled to an externally calibrated ThermoScientific LTQ Velos nLC-ESI-LIT-Orbitrap (high-resolution electrospray tandem mass spectrometer). nLC-MS/MS was run in technical triplicate for each biological replicate to enable normalization and analysis. The raw files were analyzed using the Proteome Discoverer software package (version 1.4, ThermoScientific, http://www. thermoscientific.com) with SequestHT and Mascot search nodes using species-specific FASTA database and the Percolator peptide validator. The resulting MSF files were further analyzed using the Scaffold proteome validator software (version 4.0.6.1, Proteome Software, Inc., http:// www.proteomesoftware.com/).

\section{Protein expression detection by Western blot}

Western blot analysis was performed using cultured cells at $70-80 \%$ confluence by previously described protocols [32]. In brief, $20 \mu \mathrm{g}$ of protein samples were electrophoresed on 4-15\% Bis-Tris gradient SDS-PAGE (BioRad 456-1084), transferred onto nitrocellulose membrane (BioRad 162-0115), reacted with 1:200 diluted anti-MCM3 antibody (Cell Signaling \# 4012), and followed by secondary goat anti-rabbit antibody conjugated with horseradish peroxidase (Santa Cruz sc2004). The immune-reactive bands were detected using Kodak Image Station 4000MM Pro instrument (AFAB Lab resources) and Carestream Molecular Imaging Software Network Edition.

\section{Data analysis}

Normalized spectral counts from cell proteomics were assigned to a peptide sequence with $95 \%$ confidence. A minimum of two identified peptides was required to confirm a protein sequence with $95 \%$ confidence. Missing values were imputed with the minimum non-zero normalized spectral count. An unpaired, two-sample t-test was performed on normalized spectral counts in order to determine differentially expressed proteins between $\mathrm{ARCaP}_{\mathrm{E}}$ and $\mathrm{ARCaP}_{\mathrm{M}}$, and a $\mathrm{P}$-value of $<0.05$ was used as a cutoff for statistical significance. Pathway analysis was performed using GeneGO MetaCore (Thomson Reuters, https://portal.genego.com/) on proteins with a cut-off mean expression set at least 1.5 fold difference between $\mathrm{ARCaP}_{\mathrm{E}}$ and $\mathrm{ARCaP}_{\mathrm{M}}$. 


\section{Immunohistochemistry of prostate cancer patient tissue samples and human tumors grown in nude mice}

The immunohistochemistry (IHC) staining method was the same as our previously reported protocol with minor modifications [3, 32]. Formalin-fixed paraffin embedded (FFPE) sections were deparaffinized, rehydrated, and subjected to antigen retrieval. After incubating in Dual Endogenous Enzyme Block solution (Dako, Carpinteria, CA) for 10 minutes, sections were incubated with MCM3 primary antibody (IgG from rabbits) (Cell Signaling \# 4012) and diluted with Antibody Diluent solution (Dako) at a 1:50 ratio at room temperature for two hours. The section was then washed 3 times in PBST (phosphate-buffered saline containing 0.2\% Tween 20) for 5 minutes per washing and incubated with EnVision+ Dual Link System-HRP (Dako) for 30 minutes, which contains horse radish peroxidase conjugated goat antibodies directed against rabbit IgG. Sections were washed 3 times for 5 minutes each, and stains were developed with 3,3'-diaminobenzidine (Dako). HeLa cells were used as positive control. Negative controls were performed by eliminating the primary antibody or replacing with rabbit $\mathrm{IgG}$ prepared at the same concentration and applied to an immediately adjacent tissue section.

\section{Author contributions}

Conceived and designed the experiments: PAS, HEZ, LWKC, QXAS. Performed the experiments: PAS, HEZ, PD, QL. Analyzed the data: PAS, ZIK, HEZ, PD, QL, QXAS. Contributed reagents/materials/analysis tools: PAS, HEZ, PD, QL, QXAS. Wrote the paper: PAS, ZIK, HEZ, PD, QL, LWKC, QXAS.

\section{ACKNOWLEDGMENTS}

The Joseph M. Schor Fellowship in Biochemistry from Florida State University supported PAS. This work was supported in part by a Florida State University Dissertation Research Grant to PAS and a Lebanese University grant to ZIK. This work was also supported in part by NIH NCI-P01-CA098912 to LWKC. We appreciate the generous support of Florida State University and anonymous donors for the Endowed Chair Professorship in Cancer Research to QXAS. We thank the Translational Science Laboratory at the Florida State University College of Medicine for mass spectrometry core facility support and technical assistance. We thank Dr. Gary Mawyer for English editing of the manuscript text.

\section{CONFLICTS OF INTEREST}

The authors declare no conflicts of interest.

\section{REFERENCES}

1. Siegel RL, Miller KD, Jemal A. Cancer statistics, 2016. CA Cancer J Clin. 2016; 66: 7-30.

2. Yang J, Weinberg RA. Epithelial-mesenchymal transition: at the crossroads of development and tumor metastasis. Dev Cell. 2008; 14: 818-829.

3. Zhau HE, Odero-Marah V, Lue HW, Nomura T, Wang R, Chu G, Liu ZR, Zhou BP, Huang WC, Chung LW. Epithelial to mesenchymal transition (EMT) in human prostate cancer: lessons learned from ARCaP model. Clin Exp Metastasis. 2008; 25: 601-610.

4. Josson S, Gururajan M, Hu P, Shao C, Chu GC, Zhau HE, Liu C, Lao K, Lu CL, Lu YT, Lichterman J, Nandana S, Li $Q$, et al. miR-409-3p/-5p promotes tumorigenesis, epithelial-to-mesenchymal transition, and bone metastasis of human prostate cancer. Clin Cancer Res. 2014; 20: 4636-4646.

5. Wang X, Stewart PA, Cao Q, Sang QX, Chung LW, Emmett MR, Marshall AG. Characterization of the phosphoproteome in androgen-repressed human prostate cancer cells by Fourier transform ion cyclotron resonance mass spectrometry. J Proteome Res. 2011; 10: 3920-3928.

6. Samson R, Bell S. MCM loading - an open-and-shut case? Mol Cell. 2013; 50: 457-458.

7. Chang VK, Fitch MJ, Donato JJ, Christensen TW, Merchant AM, Tye BK. Mcm1 binds replication origins. J Biol Chem. 2003; 278: 6093-6100.

8. Ricke RM, Bielinsky AK. mcm10 regulates the stability and chromatin association of DNA polymerase- $\alpha$. Mol Cell. 2004; 16: 173-185.

9. Maiorano D, Cuvier O, Danis E, Méchali M. MCM8 is an MCM2-7-related protein that functions as a DNA helicase during replication elongation and not initiation. Cell. 2005; 120: 315-328.

10. Yoshida K. Identification of a novel cell-cycle-induced MCM family protein MCM9. Biochem Biophys Res Commun. 2005; 331: 669-674.

11. Evrin C, Clarke P, Zech J, Lurz R, Sun J, Uhle S, Li H, Stillman B, Speck C. A double-hexameric MCM2-7 complex is loaded onto origin DNA during licensing of eukaryotic DNA replication. Proc Natl Acad Sci U S A. 2009; 106: 20240-20245.

12. Frigola J, Remus D, Mehanna A, Diffley JF. ATPasedependent quality control of DNA replication origin licensing. Nature. 2013; 495: 339-343.

13. Chistol G, Walter JC. Single-molecule visualization of MCM2-7 DNA loading: seeing is believing. Cell. 2015; 161: 429-430.

14. Kobierzycki C, Pula B, Skiba M, Jablonska K, Latkowski K, Zabel M, Nowak-Markwitz E, Spaczynski M, Kedzia W, Podhorska-Okolow M, Dziegiel P. Comparison of minichromosome maintenance proteins (MCM-3, MCM7) and metallothioneins (MT-I/II, MT-III) expression in 
relation to clinicopathological data in ovarian cancer. Anticancer Res. 2013; 33: 5375-5384.

15. Rezvani G, Andisheh-tadbir A, Javad M, Amanpour S, Kamali F, Fardisi S. Evaluation of minichromosome maintenance-3 (MCM3) in oral squamous cell carcinoma. J Dent Shiraz Univ Med Sci. 2015; 16: 87-92.

16. Nodin B, Fridberg M, Jonsson L, Bergman J, Uhlén M, Jirström K. High MCM3 expression is an independent biomarker of poor prognosis and correlates with reduced RBM3 expression in a prospective cohort of malignant melanoma. Diagn Pathol. 2012; 7: 82-92.

17. Zhang S, Wang X, Osunkoya AO, Iqbal S, Wang Y, Chen Z, Müller S, Josson S, Coleman IM, Nelson PS, Wang YA, Wang R, Shin DM, et al. EPLIN downregulation promotes epithelial-mesenchymal transition in prostate cancer cells and correlates with clinical lymph node metastasis. Oncogene. 2011; 30: 4941-4952.

18. Pulukuri S, Rao J. Martix matalloproteinase-1 promotes prostate tumor growth and metastasis. Int J Oncol. 2008; 32: 757-765.

19. Brussel JV, Steenbrugge GV. Expression of multidrug resistance related proteins and proliferative activity is increased in advanced clinical prostate cancer. J Urol. 2001; 165: 130-135.

20. Scheffer G, Schroeijers A, Izquierdo M. Lung resistancerelated protein/major vault protein and vaults in multidrugresistant cancer. Curr Opin Oncol. 2000; 12: 550-556.

21. Zhang S, Zhau HE, Osunkoya AO, Iqbal S, Yang X, Fan S, Chen Z, Wang R, Marshall FF, Chung LW, Wu D. Vascular endothelial growth factor regulates myeloid cell leukemia-1 expression through neuropilin-1-dependent activation of c-MET signaling in human prostate cancer cells. Mol Cancer. 2010; 9: 9.

22. Khamis ZI, Iczkowski KA, Sang QX. Metastasis suppressors in human benign prostate, intraepithelial neoplasia, and invasive cancer: their prospects as therapeutic agents. Med Res Rev. 2012; 32: 1026-1077.

23. Odero-Marah VA, Wang R, Chu G, Zayzafoon $\mathrm{M}, \mathrm{Xu} \mathrm{J}$, Shi C, Marshall FF, Zhau HE, Chung LW. Receptor activator of NF-kappaB Ligand (RANKL) expression is associated with epithelial to mesenchymal transition in human prostate cancer cells. Cell Res. 2008; 18: 858-870.

24. Zhau HY, Chang SM, Chen BQ, Wang Y, Zhang H, Kao C, Sang QA, Pathak SJ, Chung LW. Androgen-repressed phenotype in human prostate cancer. Proc Natl Acad Sci U S A. 1996; 93: 15152-15157.

25. Xu J, Wang R, Xie ZH, Odero-Marah V, Pathak S, Multani A, Chung LW, Zhau HE. Prostate cancer metastasis: role of the host microenvironment in promoting epithelial to mesenchymal transition and increased bone and adrenal gland metastasis. Prostate. 2006; 66: 1664-1673.

26. Helfenstein A, Frahm SO, Krams M, Drescher W, Parwaresch R, Hassenpflug J. Minichromosome maintenance protein (MCM6) in low-grade chondrosarcoma: distinction from enchondroma and identification of progressive tumors. Am J Clin Pathol. 2004; 122: 912-918.

27. Ren B, Yu G, Tseng GC, Cieply K, Gavel T, Nelson J, Michalopoulos G, Yu YP, Luo JH. MCM7 amplification and overexpression are associated with prostate cancer progression. Oncogene. 2006; 25: 1090-1098.

28. Padmanabhan V, Callas P, Philips G, Trainer TD, Beatty BG. DNA replication regulation protein $\mathrm{Mcm} 7$ as a marker of proliferation in prostate cancer. J Clin Pathol. 2004; 57 : 1057-1062.

29. Savagner P. The epithelial-mesenchymal transition (EMT) phenomenon. Ann Oncol. 2010; 21: vii89-vii92.

30. Shi YK, Yu YP, Zhu ZH, Han YC, Ren B, Nelson JB, Luo JH. MCM7 interacts with androgen receptor. Am J Pathol. 2008; 173: 1758-1767.

31. Wiśniewski JR, Zougman A, Nagaraj N, Mann M. Universal sample preparation method for proteome analysis. Nat Methods. 2009; 6: 359-362.

32. Hu P, Chu GC, Zhu G, Yang H, Luthringer D, Prins G, Habib F, Wang Y, Wang R, Chung LW, Zhau HE. Multiplexed quantum dot labeling of activated c-Met signaling in castration-resistant human prostate cancer. PLoS One. 2011; 6: e28670. 